\title{
Decolonising Participatory Design Practices: Towards Participations Otherwise
}

\author{
Rachel Charlotte Smith \\ Department of Digital Design and \\ Information Studies, Aarhus \\ University, Aarhus, Denmark \\ rsmith@cc.au.dk \\ Asnath Paula Kambunga \\ Department of Digital Design and \\ Information Studies, Aarhus \\ University, Aarhus, Denmark \\ akambunga@cc.au.dk
}

\author{
Heike Winschiers-Theophilus \\ Department of Computer Science, \\ Namibia University of Science and \\ Technology, Windhoek, Namibia \\ hwinschiers@nust.na \\ Marly Muudeni Samuel \\ ICT Innovation Hub, Namibia \\ University of Science and Technology, \\ Windhoek, Namibia \\ marly18samuel@gmail.com
}

\author{
Daria Loi \\ Experiences and Design, Emerging \\ Technologies, Mozilla Corp. Portland, \\ US \\ dloi@mozilla.com \\ Rogerio de Paula \\ IBM Brazil, São Paulo, Brazil \\ ropaula@br.ibm.com
}

\begin{abstract}
Participatory Design (PD) approaches are particularly well-suited to contribute to contemporary debates of decolonisation in design due to PD's long-standing political traditions and values of democracy and empowerment. Decolonising discourses teach us that we need to move away from the universalising 'grand narratives' of knowledge production and focus on contextualising diverse and situated experiences, epistemologies and narratives. Yet, few contributions actively demonstrate what a shift to decolonising PD means in practice. This interactive workshop will invigorate the gap in PD debates of decolonisation by bringing together and demonstrating how participatory designers in diverse global contexts are working with and adapting modes, concepts, methodologies and sensibilities of PD into decolonising practices. These practices not only create new shifts and worldviews, but have potential for developing truly transcultural and transdisciplinary PD approaches
\end{abstract}

\section{CCS CONCEPTS}

- Human-centered computing $\rightarrow$ Interaction design; Human computer interaction (HCI).

\section{KEYWORDS}

Decolonisation, epistemology, Methodology, Transdisciplinary, Transcultural
ACM Reference Format:

Rachel Charlotte Smith, Heike Winschiers-Theophilus, Daria Loi, Asnath Paula Kambunga, Marly Muudeni Samuel, and Rogerio de Paula. 2020. Decolonising Participatory Design Practices: Towards Participations Otherwise. In Proceedings of the 16th Participatory Design Conference 2020- Participation(s) Otherwise - Vol. 2 (PDC '20: Vol. 2), June 15-20, 2020, Manizales, Colombia. ACM, New York, NY, USA, 3 pages. https://doi.org/10.1145/ 3384772.3385172

\section{INTRODUCTION}

The workshop will engage participants in interactive activities with a focus to generate plural understandings and epistemological views through the use of PD methods. Further, it will create insights into the different ways choices are made based on diverse epistemologies, methodologies and continental demarcations. Grounded by the PDC 2020 theme of Participation(s) Otherwise, the workshop looks beyond traditional PD narratives towards adoptable PD approaches and methods within a transcultural and transdisciplinary mode. A central aim of the workshop is to gather a diversity of decolonising practices; methods, concepts and approaches applied in diverse contexts, that demonstrate research and knowledge practices for plural epistemologies, marginalised voices, situated socio-political and historical contexts, through participatory processes.

\section{DECOLONISING PARTICIPATORY DESIGN}

PD has a long history of addressing power relations and issues of democracy and empowerment with special attention to engaging local and marginalised groups, citizens and organisations in processes of mutual learning and bottom-up development [4]. Equally, the ongoing appropriation of PD outside of Scandinavia in particular to the global south, has focused on the inclusion and 'empowerment' of local communities and citizens, but also prompted critical concerns of the original Westernised model's applicability to the rest of the world $[3,22]$. The cultural lenses chosen determine our approaches to participant engagement as well as the research outcomes. A postcolonial perspective points to the fact that design practices are far from universal, and are still based on Western epistemologies and applied in developing countries without much consideration of the local knowledge systems $[5,11,12,20]$. Thus, one could argue that well intended PD practices intrinsically still promote neocolonial
Permission to make digital or hard copies of all or part of this work for personal or classroom use is granted without fee provided that copies are not made or distributed for profit or commercial advantage and that copies bear this notice and the full citation on the first page. Copyrights for components of this work owned by others than the author(s) must be honored. Abstracting with credit is permitted. To copy otherwise, or republish, to post on servers or to redistribute to lists, requires prior specific permission and/or a fee. Request permissions from permissions@acm.org.

PDC '20: Vol. 2, June 15-20, 2020, Manizales, Colombia

(C) 2020 Copyright held by the owner/author(s). Publication rights licensed to ACM. ACM ISBN 978-1-4503-7606-8/20/06 ..\$15.00

https://doi.org/10.1145/3384772.3385172 
design. Thus, the decolonising design discourse is of an ontological nature and requires a transdisciplinary and transcultural dialogue to radically transform design $[12,18]$.

Yet, there seem to be theoretical and methodological gaps in $\mathrm{PD}$ in relation to contemporary discourses of decolonising design $[17,18,20]$. Such gaps are visible also in practice in different domains, from the widespread generalisation of design methods and approaches, to non-profit organisations' commodification of aid in the underdeveloped world [11], and industry development and distribution of one-size-fits-all tech applications to the global market.

\section{DECOLONISATION PRACTICES}

The workshop examines how participatory designers are responding to the critical calls for humanistic, contextualised and dewesternising approaches to design and development across local and regional research contexts. Based on promising examples of decolonising directions on different continents, described in the following, we aim to create a basis for evolving decolonising PD practices connected to such domains as:

Transcultural technology design: Community engagement through a transcultural approach, looks beyond traditional individual cultures and focuses on transcultural technology design methods that adopt, support and continuously create new meanings from diverse settings. A transcultural approach focuses on being culturally aware when designing with culturally diverse communities and groups, embracing pluralistic social practices and increased awareness [23].

Localisation of knowledge: Through promotion of local conferences such as AfriCHI and other initiatives to support strong local research communities. ICT4D though engaged in local initiatives to support development is often still based on Western ideals and evaluation parameters of the developing world [10]. Incorporating local practices and values, such as the suggested afrocentric approach to HCI [21] promotes alternative knowledge creations.

Humanising emerging technology: An increasing number of debates around inherent biases in AI, cultural variations in the ethical debates of autonomous vehicles and social robots suggest the realisation for action $[8,13]$. Like design, algorithms and intelligent systems are important sites of cultural transformation, and participatory designers and researchers are working against the colonial impulse in ubiquitous computing [9], to develop human, ethical and responsible approaches, principles and guidelines for decolonising emerging technologies in corporate contexts $[2,16,17]$.

Participatory action research: Historical traditions such as participatory action research in Latin America echo strong decolonising practices that focus on the social realities, political struggles and empowerment of marginalised communities [6, 12, 14]. Where some contributions suggest the systematisation of experience to validate alternative southern epistemologies, Escobar argues for notions of 'pluriversal design' [11]; creating a world in which 'many worlds fit' and that allow the emergence of pluriversal ways of worldmaking. Notions of autonomous design are integral and should support the self-realisation of communities based on southern approaches [7].

Design anthropology futures: Contributions from design anthropology offer decolonising approaches to the situated ethics, values and politics of future making [15, 19, 22]. Researchers use anthropological approaches and cultural sensibilities to create 'correspondence' through a continued engagement and commitment to particular people and lifeworlds [15]. Through collaborative explorations of emergent cultural practices, possible futures are cocreated that are deeply aligned with local epistemologies. Such sensitivity relates also to Akama's [1] use of the Japanese concept of $M a$, 'between-ness', to explore how designers can work through processes of becoming together.

The transdisciplinary and culturally situated approaches to knowledge production have potential for generating new understandings and practices in the decolonisation of PD. To identify and map possible decolonising practices in transcultural and transdisciplinary settings, four questions are addressed:

- What are state-of-the-art examples of decolonising practices and epistemologies in/for contemporary PD research and practice?

- What can we learn from PD experiences of decolonising practices applied in diverse contexts; geographical, academic, corporate, not for profit?

- How are theoretical discourses of decolonisation integrated into concrete practices, methodologies, or modes of knowledge production in the research?

- What are the future trajectories of decolonising PD practices for pluriversal approaches to design and technology?

\subsection{Workshop format}

Building on the above arguments and directions for decolonisation, this full day workshop has different phases.

Phase 1: PD of a social robot [[2] hours]: Participants are grouped in smaller groups and immediately engaged in the codesign of a social robot for defined diverse contexts (be it organisational, community, private or public spaces). The design techniques will be "borrowed" from the suggested methods in the position papers and/or prescribed by the organisers such as using "consensus method" in one group, but also allowing the participants to negotiate design methods [[1] hour]. Only once the groups share their design outputs with the rest of the group do they reveal who they are and position their research in relation to their created robots, their personal values and views [[1]hour].

Phase 2: Embracing epistemologies dialogue [1.5 hours]: The plurality of epistemologies in the room are now made explicit triggered by the created artefacts and attached values. Each participant will position themselves, map out their methods or concepts, and express how they create knowledge looking at phase 1, a research through design approach. Possible decolonisation of PD practices are presented in form of an engaged Bohm dialogue.

Phase 3: Prototype decolonising toolkit [1.5 hours]: In groups the participants will prototype a toolkit of methods, techniques, concepts and principles of a decolonised PD. The toolkit will be showcased to a wider PDC audience in an exchange event with other workshop participants.

\section{PARTICIPANTS RECRUITMENT}

The minimum number of participants is 5 and the maximum number of participants 25. Participants will be asked to provide 1-2-page 
Table 1: Workshop schedule

\begin{tabular}{ll}
\hline Workshop Activity & Time \\
\hline $\begin{array}{l}\text { Introduction of workshop format and } \\
\text { content by organisers }\end{array}$ & $15 \mathrm{~min}$ \\
PD of a social robot in smaller groups & $60 \mathrm{~min}$ \\
Sharing of products and introduction of & $60 \mathrm{~min}$ \\
participants and organisers & $90 \mathrm{~min}$ \\
$\begin{array}{l}\text { Dialogue embracing epistemologies } \\
\text { Prototype toolkit of methods }\end{array}$ & $90 \mathrm{~min}$ \\
Summary conclusion and way forward & $30 \mathrm{~min}$ \\
\hline
\end{tabular}

position papers describing examples of rich on-the-ground research cases that demonstrate or conceptualise decolonising approaches and practices to design and technology. The participants are requested to elaborate on their own practical experience as well as provide suggestions for possible methods, techniques and concepts aiming at embracing multiple epistemologies in design and knowledge production. The aim is to attract diverse participants from different continents, that represent a global community of PD researchers working in different contexts and domains.

\section{OUTCOME OF THE WORKSHOP}

The workshop will produce a collection of decolonising approaches and methods from a diverse PD global community. Multiple joint article(s) or a journal SI, will be generated after the workshop that discuss and reflect upon this collection and collaborative decolonising toolkit.

\section{ORGANISERS}

The authors represent diverse disciplines and approaches across design, anthropology, technology and innovation, from Africa, Latin America, Europe and the US.

Rachel Charlotte Smith is Associate Professor at the Dept. of Digital Design and Information Studies at Aarhus University. Her research focuses on participatory and design anthropological modes of research, social transformation and future making. Heike Winschiers-Theophilus is a Professor in Computer Science at the Namibia University of Science and Technology. Her work revolves around community-based co-design with indigenous and marginalised people. She promotes a transcultural approach to technology design. Daria Loi is Senior Director at Mozilla, where she heads the Experiences \& Design organisation. Her work revolves around mixing design strategy with user experience research to enrich people's everyday life, with an emphasis on Emerging Technologies. Asnath Paula Kambunga is a Marie Curie $\mathrm{PhD}$ fellow at the Dept. of Digital Design and Information Studies at Aarhus University. Her research interest lies in working with youth communities and collaborative explorations of future memories making. Marly Muudeni Samuel is a Tech Innovation Coordinator at the Inclusive \& Collaborative Tech Hub in Windhoek, Namibia. She is passionate about information access, and how innovation and co-design can empower youth and advance education. Dr. Rogerio de Paula is a senior research scientist at IBM Research Brazil, and manager of the Visual Analytics \& Insights Research Group. His main research interest is in the intersection of $\mathrm{AI}$ and human machine interaction, and design for social good.

\section{REFERENCES}

[1] Yoko Akama. 2015. Being awake to Ma: designing in between-ness as a way of becoming with. CoDesign 11, 3-4: 262-274. https://doi.org/10.1080/15710882.2015. 1081243

[2] Sareeta Amrute. 2019. Tech Colonialism Today. Retrieved from https://2019. epicpeople.org/keynotes/\#amrute

[3] Liam Bannon, Jeffrey Bardzell, and Susanne Bødker. 2018. Reimagining participatory design. Interactions 26, 1: 26-32. https://doi.org/10.1145/3292015

[4] Liam J Bannon and Pelle Ehn. 2013. Design: Design Matters in Participatory Design. In Routledge International Handbook of Participatory Design. Routledge, 37-63.

[5] Nicola J. Bidwell. 2016. Decolonising HCI and interaction design discourse: some considerations in planning AfriCHI. XRDS: Crossroads, The ACM Magazine for Students 22, 4: 22-27. https://doi.org/10.1145/2930884

[6] Orlando Fals Borda. 1979. Investigating reality in order to transform it: The Colombian experience. Dialectical Anthropology 4, 1: 33-55. https://doi.org/10. 1007/BF00417683

[7] Pablo Calderón Salazar, Mela Zuljevic, and Liesbeth Huybrechts. 2018. Southern manners in northern lands: Design interventions for autonomía. Strategic Design Research fournal 11, 2. https://doi.org/10.4013/sdrj.2018.112.06

[8] Paul Dourish and Genevieve Bell. 2011. Divining a digital future: mess and mythology in ubiquitous computing.MIT Press, Cambridge, Mass.

[9] Paul Dourish and Scott D. Mainwaring. 2012. Ubicomp's colonial impulse. In Proceedings of the 2012 ACM Conference on Ubiquitous Computing - UbiComp '12, 133. https://doi.org/10.1145/2370216.2370238

[10] Arturo Escobar. 2012. Encountering development: the making and unmaking of the third world. Princeton University Press, Princeton, N.J.

[11] Arturo Escobar. 2015. Transiciones: a space for research and design for transitions to the pluriverse. Design Philosophy Papers 13, 1: 13-23. https://doi.org/10.1080/ 14487136.2015.1085690

[12] Arturo Escobar. 2018. Designs for the pluriverse: radical interdependence, autonomy, and the making of worlds. Duke University Press, Durham.

[13] Ed Finn. 2017. What algorithms want: imagination in the age of computing. MIT Press, Cambridge, MA.

[14] Paulo Freire. 1998. Pedagogy of freedom: ethics, democracy, and civic courage. Rowman \& Littlefield Publishers, Lanham.

[15] Wendy Gunn, Ton Otto, and Rachel Charlotte Smith (eds.). 2013. Design anthropology: theory and practice. Bloomsbury, London; New York.

[16] Daria Loi, Thomas Lodato, Christine T. Wolf, Raphael Arar, and Jeanette Blomberg. 2018. PD manifesto for AI futures. In Proceedings of the 15th Participatory Design Conference on Short Papers, Situated Actions, Workshops and Tutorial-PDC '18, 1-4. https://doi.org/10.1145/3210604.3210614

[17] Henry Mainsah and Andrew Morrison. 2014. Participatory design through a cultural lens: insights from postcolonial theory. I $n$ Proceedings of the 13th Participatory Design Conference on Short Papers, Industry Cases, Workshop Descriptions, Doctoral Consortium papers, and Keynote abstracts - PDC '14 - volume 2, 83-86. https://doi.org/10.1145/2662155.2662195

[18] Tristan Schultz, Danah Abdulla, Ahmed Ansari, Ece Canll, Mahmoud Keshavarz, Matthew Kiem, Luiza Prado de O. Martins, and Pedro J.S. Vieira de Oliveira. 2018. What Is at Stake with Decolonizing Design? A Roundtable. Design and Culture 10, 1: 81-101. https://doi.org/10.1080/17547075.2018.1434368

[19] Rachel Charlotte Smith, Kasper Tang Vangkilde, Mette Gislev Kjaersgaard, Ton Otto, Joachim Halse, and Thomas Binder (eds.). 2016. Design anthropological futures: exploring emergence, intervention and formation. Bloomsbury Academic, an imprint of Bloomsbury Publishing, Plc, London; New York.

[20] Rachel Charlotte Smith, Heike Winschiers-Theophilus, Asnath Paula Kambunga, and Sarala Krishnamurthy. 2020. Decolonising Participatory Design: Memory Making in Namibia. Participatory Design Conference 2020 - Participation(s) Otherwise 1. https://doi.org/10.1145/3385010.3385021

[21] Elizabeth Tunstall. 2013. Decolonizing Design and Innovation: Design Anthropology, Critical Anthropology, and Indigenous Knowledge. In Design Anthropology: Theory and Practice. 232-250.

[22] Heike Winschiers-Theophilus and Nicola J. Bidwell. 2013. Toward an Afro-Centric Indigenous HCI Paradigm. International fournal of Human-Computer Interaction 29, 4: 243-255. https://doi.org/10.1080/10447318.2013.765763

[23] Heike Winschiers-Theophilus, Tariq Zaman, and Colin Stanley. 2019. A classification of cultural engagements in community technology design: introducing a transcultural approach. AI \& SOCIETY 34, 3: 419-435. https://doi.org/10.1007/s00146017-0739-y 